not to those of the chimpanzee. If human satellite II-like sequences are present in the chimpanzee, they must be there in very small amounts, a finding that is supported by the absence of much 5-methylcytosine, a rare base which is abundant in human satellite II.

Dr Seuánez is at his best when describing his own studies with the orangutan, in which he has shown that animals from Borneo and Sumatra differ by a pericentric inversion (perhaps marking incipient species), but that each population is still heterozygous for a different complex chromosomal rearrangement. In this volume he has included a wealth of information about a broad range of techniques. Students and those interested in primate cytogenetics will find the volume useful because it includes a large number of references, although a single reference list would have been easier to use than will be the separate list presented after each short chapter. General interest readers will probably be disappointed by the book because the broader aspects of phylogeny have been submerged in the sea of minute details. A final chapter drawing together information derived from the various methods would have been a welcome addition. Most of the illustrations are well designed, but the chromosomes in some of the composite karyotypes are so small that they present little information. Unfortunately there are a large number of typographical errors which distract attention from the message of the text.

Dorothy A. Miller is Assistant Professor in the Department of Human Genetics and Development at Columbia University, New York.

\section{Basic molecular biology}

\section{G.C. Walker}

Basic Molecular Biology. By Fred W. Price. Pp.497. (Wiley: New York, 1979.) $\$ 20.50$.

BASIC MOLECULAR BIOLOGY by F.W. Price is intended to be a suitable text for freshmen with a background in general biology and chemistry. The book opens with an extremely elementary introduction to basic chemical principles and then is divided into four main sections. The first section, which comprises almost half of the book, discusses primary through to quaternary structures of proteins, and the relationship of structure to function. One chapter provides a particularly clear general introduction to enzymes and others discuss topics such as fibrous protein assemblies and antibodies. The second section covers the structure of biomembranes and biological energy transducers. The third section covers the structures and roles of nucleic acids in the storage and expression of genetic information. A somewhat speculative chapter on chromatin structure is included. The final section is quite broad and considers the organisation of prokaryotic and eukaryotic cells.

In his preface, Price states that his approach is 'structural'. Indeed, almost every topic is introduced by a consideration of the relevant chemical and structural parameters of the molecule or assembly in question. Since the author has also intentionally minimised the attention paid to molecular genetics and protein synthesis, the book is much closer in many respects to a biochemistry text than to books such as Molecular Biology of the Gene (Watson; W.A. Benjamin: Menlo Park, California, 1976) or Molecular Genetics (Stent and Calendar; Freeman: San Francisco, 1978). In particular, while genetics is treated as a subject in one chapter, very few genetic experiments or approaches are discussed elsewhere. Knowledge of basic organic chemistry is required throughout.

The book is clearly written and profusely illustrated. Occasional touches of humour help personalise the text. However, greater care in the relative emphasis given to specific examples would have improved the book. For example, several pages are devoted to the physical parameters of invertebrate oxygen-transporting proteins yet the discussion of ATCase in the section on allosteric enzymes is very short and has no illustrations. Other examples discussed, such as that of resilin, seem to contribute little to an introductory text.
Price also comments that, in writing an introductory text, he has resisted the temptation to delve deeply into certain exciting aspects of molecular biology. Nevertheless, I was disappointed that a number of the models discussed in detail seemed quite dated and were presented in an uncritical fashion, and also that such a recent book did not even allude to current topics such as recombinant DNA, DNA sequencing, the Ames test, or hybridomas.

G.C. Walker is an Assistant Professor in the Biology Department, Massachusetts Institute of Technology, Cambridge, Massachusetts.

\section{Views of enzymes}

\section{Dennis Piszkiewicz}

Steady-State Enzyme Kinetics. By Stanley Ainsworth. Pp.255. (University Park Press: Baltimore; Macmillan: London, 1977.) \$17.50. Enzymatic Reaction Mechanisms. By C. Walsh. Pp.978. (Freeman: San Francisco and Reading, 1979.) \$29.50. Principles of Enzymatic Analysis. Edited by H.U. Bergmeyer and K. Gawehn. Pp.260. (Verlag Chemie: Weinheim, 1978.) \$25.90.

IN the past two decades our understanding of the nature and properties of enzymes has grown at a prodigious rate. The availability of texts describing these advances is now catching up with this growth. In recent years we have been treated to a large and somewhat redundant supply of texts on enzyme kinetics and mechanisms, albeit of varying scopes, lengths and quality. Three recent and different approaches to enzymology are examined here.

Kinetics observes catalysis in the time scale in which it occurs. It is the most important and popular tool available for the elucidation of enzymatic mechanisms.
Steady-State Enzyme Kinetics by Stanley Ainsworth presents an up to date survey of the mathematical gymnastics used to analyse enzyme kinetic data. It emphasises the methods of deriving models that describe the orders and methods of interaction of substrates and effectors to the catalytic molecules. The major fault of this text is that it really does not address the purpose of enzyme kinetics - the definition of the mechanism of catalysis in as much detail as possible. It barely touches on subjects such as kinetic evidence of enzyme-substrate intermediates, $p \mathrm{H}$ dependencies, and so on, which can be related to the bondforming and bond-breaking steps. It is unsettling to realise how so much sophisticated analysis can yield so little understanding of the forces being studied. In a review of Irwin H. Segal's Enzyme Kinetics (Wiley: New York, 1975), a text of similar scope, S.E. Halford (Nature 259, $255 ; 1976)$ noted that enzyme kinetics is a tool of biochemical research, not an intellectual discipline in its own right. Even as a tool, Segal's Enzyme Kinetics is more detailed and more accessible than this newer volume.

The results of the efforts of legions of enzymologists are brought together in Enzymatic Reaction Mechanisms by Christopher Walsh. This text, as the author notes in his preface, developed from his 